\section{Alternative methods to overcome the challenging anatomy of the coronary sinus during percutaneous mitral annuloplasty procedure (4)}

\author{
Suat Görmel (D), Salim Yaşar (D), Ender Murat (D), Ozan Köksal (iD, \\ Uygar Çağdaş Yüksel (D), Cem Barçın (D), Murat Çelik (D) \\ Department of Cardiology, University of Health Sciences, Gülhane Training \\ and Research Hospital; Ankara-Turkey
}

\section{Introduction}

Dilated cardiomyopathy (DCM) is usually associated with variable degrees of functional mitral regurgitation (FMR), which contributes to higher morbidity and mortality. At present, the optimal management strategy for FMR is not clearly defined in the guidelines. A variety of percutaneous valve interventions to improve patients' quality of life and decrease morbidity and mortality have been developed recently. The CARILLON Mitral Contour System is a fully transvenous approach using the anatomical proximity of the coronary sinus (CS) to the mitral annulus. In this technique, a device consisting of distal and proximal anchors linked by a flexible nitinol clip is introduced via the CS to encircle around two thirds of the mitral annulus, thereby, creating a tension constricting the mitral annulus (1). When properly deployed within the CS, it can lead to marked symptomatic and functional improvement with a low rate of major adverse events (1-3).

\section{Case Report}

A 74-year-old female with ischemic heart failure with New York Heart Association class III dyspnea was referred to our clinic. Despite optimal medical treatment, the patient was still symptomatic. ECG showed normal sinus rhythm. There were left ventricular dilatation, very poor LV systolic function (ejection fraction $15 \%$ ), and severe FMR on transthoracic echocardiography. Similarly, a transesophageal echocardiogram showed severe FMR with a dilated mitral annulus measuring $49 \mathrm{~cm}$, vena contracta of $10 \mathrm{~mm}$, and no structural abnormality of the mitral valve apparatus. Because of the high surgery risk, the heart team of our institute decided on percutaneous mitral annuloplasty with CARILLON Mitral Contour System (Cardiac Dimensions Inc., Kirkland, WA, USA).

The procedure was done with local anesthesia. Venous access is obtained with a $10 \mathrm{Fr}$ sheath in the right internal jugular vein. Adequate heparinization with 10,000 IU was achieved. The venous phase of the left coronary angiogram was used as an angiographic guide for CS ostium location. We tried to later cannulate the CS using the standard techniques of telescoping system of the 9 F delivery catheter, 6 F MPA-1 diagnostic cath-

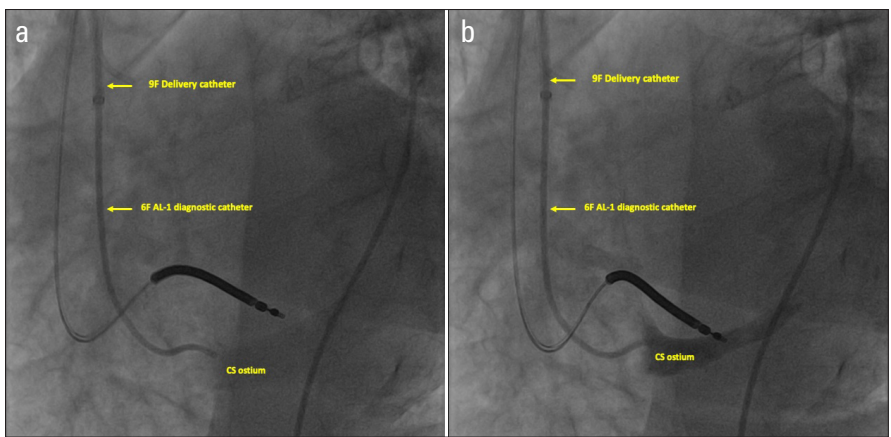

Figure 1. Cannulating the coronary sinus ostium with a $6 \mathrm{~F}$ diagnostic $\mathrm{AL}-1$ catheter through the $9 \mathrm{~F}$ delivery catheter (a), and confirming that the catheter is in the right place using slight contrast (b)

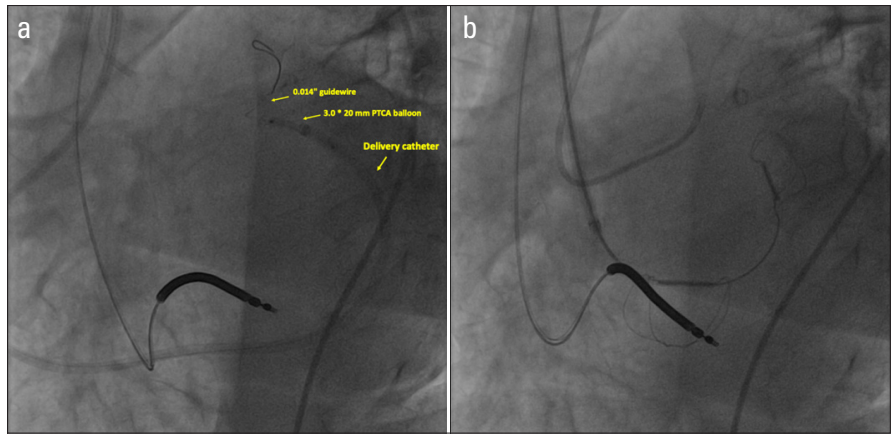

Figure 2. Balloon-assisted tracking technique using a $3.0 \times 20 \mathrm{~mm}$ coronary balloon advanced over the 0.014 " coronary angioplasty guidewire and inflated to $8 \mathrm{~atm}$ (half inside and half prolapsing outside the tip of the delivery catheter) (a) and final image of the successfully deployed CARILLON Mitral Contour System (b)
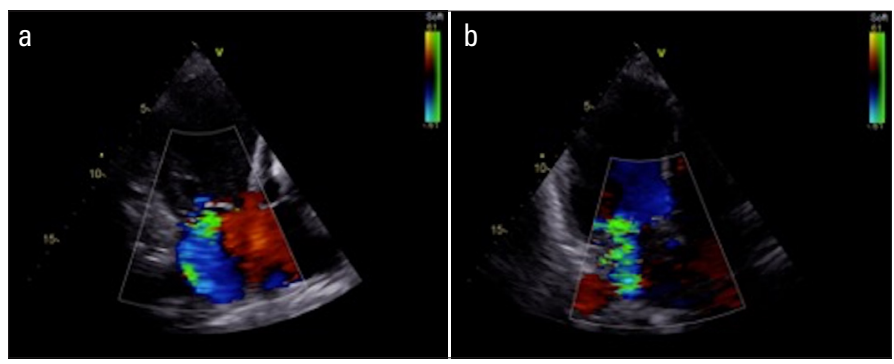

Figure 3. Echocardiographic image of mitral regurgitation before (a) and after the procedure (b)

eter, and $0.035 "$ hydrophilic guidewire. Despite many attempts, we did not succeed in cannulating the CS ostium with this equipment mostly probably owing to the highly dilated right atrium, the delivery catheter did not provide the support and direction that we needed. As an alternative method, we tried to cannulate the CS with a $6 \mathrm{~F}$ diagnostic AL-1 catheter through the delivery catheter with slight contrast, and we succeeded (Fig. 1a, 1b, Video 1). However, this time, we had difficulty advancing the delivery catheter over the diagnostic catheter within the mid-segment of the CS. The balloon-assisted tracking technique was then used to maintain the procedure. The 0.035 " hydrophilic guidewire was retrieved, and a 0.014 " coronary angioplasty guidewire was 
advanced through the delivery catheter. A $3.0 \times 20 \mathrm{~mm}$ coronary balloon was inflated to $8 \mathrm{~atm}$ (half inside and half prolapsing outside the tip of the delivery catheter); and subsequently, the delivery catheter was easily advanced to the distal end of the CS (closer to the great cardiac vein/ anterior interventricular vein junction) (Fig. 2a, Video 2). The process was then carried out in a standard manner. After venography with a marked pigtail catheter, an appropriately sized implant $(13 \times 20 \times 70 \mathrm{~mm}$ device $)$ was selected (Fig. 2b). Adequate tension with traction of the delivery system facilitated the plication of the peri-mitral annular tissue resulting in a decrease in the degree of MR on echocardiography (Fig. 3a, 3b, Videos 3, 4). Before completion of the procedure, coronary angiography was performed to ensure lack of coronary artery compression by the device. The total duration of the procedure was 84 minutes. The total fluoroscopy time was 46 minutes.

\section{Discussion and Conclusion}

The percutaneous mitral annuloplasty technique using CS faces some anatomic challenges, which might limit the success of the procedure. The main limitation is the variability in coronary venous anatomy, such as the presence of venous valves within the coronary veins and the variability of the crossing point of the great cardiac vein and circumflex artery $(4,5)$. In addition, an enlarged right atrium in the setting of DCM may result in difficulty to advance the catheters into the CS possibly owing to insufficient support. Alternative methods such as using AL-1 diagnostic catheter instead of MPA-1 for cannulating the CS ostium and/or using balloon-assisted tracking technique for advancing the delivery catheter through the CS can overcome the challenging CS anatomy. We also believe that these alternative methods can be easily used in other CS based interventions to increase the success of the procedure.

Informed consent: Informed consent was obtained from the patient for this manuscript.
Video 1. Cannulation of the coronary sinus ostium with a $6 \mathrm{~F}$ diagnostic AL-1 catheter through a 9F delivery catheter confirmed using a slight contrast

Video 2. The 9F delivery catheter being easily advanced to the distal end of the coronary sinus using balloon-assisted tracking technique with a $3.0 \times 20 \mathrm{~mm}$ coronary balloon advanced over the 0.014 " coronary angioplasty guidewire

Video 3. Echocardiographic image of mitral regurgitation before the procedure

Video 4. Echocardiographic image of mitral regurgitation after the procedure

\section{References}

1. Witte KK, Lipiecki J, Siminiak T, Meredith IT, Malkin CJ, Goldberg SL, et al. The REDUCE FMR Trial: A Randomized Sham-Controlled Study of Percutaneous Mitral Annuloplasty in Functional Mitral Regurgitation. JACC Heart Fail 2019; 7: 945-55. [Crossref]

2. Schofer J, Siminiak T, Haude M, Herrman JP, Vainer J, Wu JC, et al. Percutaneous mitral annuloplasty for functional mitral regurgitation: results of the CARILLON Mitral Annuloplasty Device European Union Study. Circulation 2009; 120: 326-33. [Crossref]

3. Siminiak T, Wu JC, Haude M, Hoppe UC, Sadowski J, Lipiecki J, et al. Treatment of functional mitral regurgitation by percutaneous annuloplasty: results of the TITAN Trial. Eur J Heart Fail 2012; 14: 931-8. [Crossref]

4. Block PC. Percutaneous mitral valve repair: are they changing the guard? Circulation 2005; 111: 2154-6. [Crossref]

5. El Said AM, Chase D, Al Rawahy NZ. Percutaneous Carillon Mitral Contour System Deployment Followed by CRT-D Implantation: First Case Report from Oman. Oman Med J 2018; 33: 531-4. [Crossref]

Address for Correspondence: Dr. Murat Çelik,

Sağlık Bilimleri Üniversitesi, Gülhane Eğitim ve Araştırma Hastanesi, Kardiyoloji Anabilim Dalı, Ankara-Türkiye

Phone: +90 5054926210

E-mail: drcelik00@hotmail.com

CCopyright 2021 by Turkish Society of Cardiology -

Available online at www.anatoljcardiol.com

DOI:10.5152/AnatolJCardiol.2021.136 